\title{
Occurrence of dermatophytoses in patients from the Sistema Único de Saúde*
}

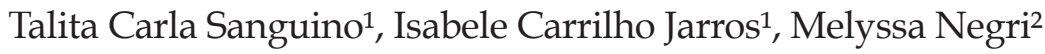

DOI: http:/ / dx.doi.org/10.1590/abd1806-4841.20197491

\begin{abstract}
BACKGROUND: Dermatophytosis is a cutaneous disease caused by filamentous keratinophilic fungi belonging to the genera Trichophyton, Microsporum and Epidermophyton, which present a high prevalence in the general population, being among the most common mycoses affecting about $20 \%$ of the world's population.

ОвлестіVE: To carry out the epidemiological survey of cases of dermatophytosis in patients from the Sistema Único de Saúde in a regional Laboratory in the period of 5 years (2009 to 2013).

Methods: A retrospective study (January 2009 to December 2013) was carried out with a qualitative and quantitative design, through the registry book of the laboratory, Mycology Sector, where cases of patients with suspected dermatomycosis were analyzed.

RESULTS: In a 5-year period, a total of 4467 cases were suspected of having a fungal infection. Of these, 68.74\% (3071) cases were of dermatomycosis. In relation to cultures with fungal growth, $12.54 \%$ (385 cases) were dermatophyte fungi and $7.97 \%$ (245 cases) non-dermatophyte fungi were isolated. Among the species identified, there was a higher prevalence of T. rubrum complex (75\%), T. mentagrophytes complex (11.68\%) and M. canis (7.01\%). Regarding the sites analyzed, nail involvement was the most frequent in $75 \%$ of the cases.

STUDy Limitations: This work is representative in the studied region.

CONCLUSIONS: Dermatomycosis samples are the most frequent among all samples of fungal infections from these patients, with the nail being the most affected area and the fungi T. rubrum complex and T. mentagrophytes complex the most frequent.

Keywords: Dermatomycoses; Epidermophyton; Microsporum; Trichophyton
\end{abstract}

\section{INTRODUCTION}

Cutaneous mycosis or dermatomycosis encompasses a large variety of diseases involving dermatophyte fungi, yeasts and filamentous non-dermatophyte fungi. These fungi infect the keratinized layer of the skin, nails and hair, usually restricted to the stratum corneum and may lead to different pathological changes in the host due to susceptibility factors, infectious agents and corresponding metabolic products. ${ }^{1}$ Epidemiological studies have shown that these are the most common dermatological mycosis, affecting nearly $20 \%$ of the worldwide population, particularly in tropical and subtropical regions..$^{2-5}$
Filamentous fungi of the genera Trichophyton, Microsporum and Epidermophyton are in the group of dermatophyte organisms. Dermatophyte fungi have been described as the main etiologic agents of dermatomycosis, followed by yeasts and filamentous non-dermatophyte fungi; however, the frequency and distribution of dermatophytosis, along with its etiologic agents vary according to the geographical region, climate conditions, cultural factors, patterns of population migration and socioeconomic level of the population. ${ }^{6-8}$ According to the literature, young adults present mainly with infections in the nails whereas children, in the hair. ${ }^{9}$

Received 28 July 2017.

Accepted 14 February 2018.

Work conducted at the Laboratory of Medical Mycology, Universidade Estadual de Maringá, Maringá (PR), Brazil.

Financial support: None.

Conflict of interest: None.

Department of Clinical Analyses and Biomedicine, Universidade Estadual de Maringá, Maringá (PR), Brazil.

Department of Clinical Analyses and Biomedicine, Laboratory of Medical Mycology, Universidade Estadual de Maringá, Maringá (PR), Brazil.

MAILING AdDRESS:

Melyssa Fernanda Norman Negri Grassi

E-mail: melyssanegri@gmail.com

(C2019 by Anais Brasileiros de Dermatologia 
Since dermatophytosis has a high prevalence, affecting both children and adults particularly in tropical climates, the aim of this study was to evaluate the occurrence and etiology of dermatophytosis in patients of the Sistema Único de Saúde seen at a regional laboratory from 2009 to 2013 in order to contribute with better knowledge and better prevention of dermatomycosis in the region.

\section{METHODS}

Area of study, population studied and ethics committee:

We conducted a retrospective, exploratory study (January 2009 to December 2013), with qualitative and quantitative design of all patients seen during this period in a laboratory of clinical analysis, with suspected and confirmed diagnosis of dermatomycosis through the registry book of the Mycology Sector.

This laboratory receives patients from the Sistema Único de Saúde (SUS), who belong to health units of over 100 municipalities linked to the Northeast macro region of the State of Paraná, of which Maringá is the headquarters. The data generated by the service support treatment of the patients seen by the SUS.

The inclusion of data complied with the rules of the commission of ethics in research involving human beings of the University where the study was conducted. The data collected were kept in strict confidentiality, with no identification. The ethical attitude met the CNS-MS 196/1996 resolution. This way, the present study was submitted to the evaluation of the permanent committee of ethics in research involving human beings (COPEP), report number 615.643.

\section{Sample:}

The data were obtained from patients seen at the laboratory with suspected and confirmed diagnosis of dermatomycosis. Information such as: age, sex, site of the lesion, direct microscopy and species were collected from the registry book.

\section{Statistical analysis:}

The statistical significance in the value differences of the frequencies found was evaluated with the chi-square test $\left(x^{2}\right)$, with $95 \%$ confidence $(p<0.05)$. Data were analyzed with the software Prism 6.0 (GraphPad, San Diego, CA, USA).

\section{RESULTS}

In a period of five years, there was a total of 4467 cases with suspected fungal infection. Of those, 3071 cases $(68.74 \%)$ were suspected dermatomycosis. For 1297 patients (42.23\%), direct microscopy examination (DME) without culture was requested, with 760 positive cases $(58.6 \%)$ and 537 negative cases (41.4\%). Of the cases that had DME and culture requested (1774), 632 (35.62\%) patients were positive for dermatomycosis. Therefore, among the suspected dermatomycosis cases (3071 cases), 12.21\% were dermatophytosis and $8.37 \%$ cases were positive for non-dermatophyte fungi. Of those 1392 patients positive for dermatomycosis (positive DME and/or culture), 375 dermatophytes were isolated, with a prevalence of 118 (31.47\%) fungi in 2009, 61 (16.27\%) fungi in 2010, 68 (18.13\%) fungi in 2011, 52 (13.87\%) fungi in 2012 and 76 (20.26\%) fungi in 2013 (Table 1).

Regarding the patients, female gender had a higher frequency for dermatophytosis in all years, with 216 cases (57.6\%), and 159 cases $(42.4 \%)$ in males, although not significant $(p>0.05)$.

Among the dermatophyte species identified, T. rubrum complex affected $73.6 \%$ of the patients $(p<0.0001) ;$ T. mentagrophytes complex, $11.47 \%$ of the patients; M. canis, $8.27 \%$ of the patients; T. tonsurans, $2.13 \%$ of the patients; T. cutaneum, $1.87 \%$ of the patients; E. floccosum, $0.80 \%$ of the patients; T. terrestre, $0.53 \%$ of the patients; M. ferrugineum, $0.53 \%$ of the patients; and the species T. gloriae, T. raubitschekii and $T$. flavescens affected only one patient each, corresponding to a total of three $(0.8 \%)$ patients (Table 1$)$.

Regarding the site of the lesion, the nails were the most frequent, with 248 (66.13\%) cases, followed by the skin with $93(24.8 \%)$ and hair, with 34 (9.07\%) cases of dermatophytosis. The agent T. rubrum complex affected mainly the nails $(67.75 \%$ or $187 / 276)$, whereas $M$. canis affected mainly the hair $(90.32 \%$ or $28 / 31)$ (Table 2$)$. Regarding the age, the agent $T$. rubrum complex was the most common in adults $(\mathrm{p}<0.0005)$, with $73.91 \%$ of cases $(204 / 276)$ in patients aged $20-59$ years. $M$. canis infection affected 29 patients, i.e., $93.55 \%$ $(29 / 31)$ of the cases in children aged $0-11$ years $(p<0.0005)$ (Table 3$)$.

TABLE 1: Description of dermatophytes per year, isolated from patients seen at the Laboratory of Teaching and Research in Clinical Analysis, Universidade Estadual de Maringá (PR) during a 5-year period (2009 to 2013)

\begin{tabular}{|c|c|c|c|c|c|c|}
\hline \multirow[t]{3}{*}{ Agent } & \multicolumn{6}{|c|}{ Year } \\
\hline & 2009 & 2010 & 2011 & 2012 & 2013 & Total \\
\hline & $\mathbf{N}(\%)$ & $\mathbf{N}(\%)$ & $\mathbf{N}(\%)$ & $\mathbf{N}(\%)$ & $\mathbf{N}(\%)$ & $\mathbf{N}\left(\%{ }^{* *}\right)$ \\
\hline T. rubrum complex & $86(31.16)$ & $45(16.30)$ & $49(17.75)$ & $44(15.95)$ & $52(18.84)$ & $276^{*}(73.6)$ \\
\hline T. mentagrophytes complex & $18(41.86)$ & $7(16.28)$ & $7(16.28)$ & $4(9.30)$ & $7(16.28)$ & $43(11.47)$ \\
\hline M. canis & $6(19.35)$ & $4(12.90)$ & $11(35.48)$ & $1(3.22)$ & $9(29.05)$ & $31(8.26)$ \\
\hline T. tonsurans & $3(37.50)$ & $0(0)$ & $0(0)$ & $1(12.50)$ & $4(50)$ & $8(2.13)$ \\
\hline T. cutaneum & $3(42.87)$ & $2(28.57)$ & $1(14.28)$ & $1(14.28)$ & $0(0)$ & $7(1.87)$ \\
\hline E. floccosum & $0(0)$ & $1(33.33)$ & $0(0)$ & $1(33.33)$ & $1(33.33)$ & $3(0.8)$ \\
\hline Outros* & $2(28,57)$ & $2(28,57)$ & $0(0)$ & $0(0)$ & $3(42,86)$ & $7(1.87)$ \\
\hline
\end{tabular}

*Others: T. gloriae, T. raubitschekii, T. flavescens, T. terrestre, M. ferrugineum

$(\% * *)$ : percentage relative to the total number of isolates (375)

$\mathrm{N}$ : number of samples with positive culture for the specific agent $\left({ }^{*} \mathrm{p}<0.05\right)$ 


\section{DISCUSSION}

Worldwide, dermatophytosis continue to be a common disease among human beings. It is estimated that around 10\% to $15 \%$ of the world's population can be infected by dermatophytes along their lives. ${ }^{4}$ Factors such as geographical region, climate conditions, cultural factors, migration patterns, socioeconomic level of the population and hygiene practices contribute to the epidemiological variation of dermatophytosis. Thus, when establishing a population profile, it is possible to adopt prophylactic measures to be implemented in the community to reduce these rates. ${ }^{10-12}$

When we analyze the results of positive cultures in a five-year period (2009-2013) of the samples from the laboratory, dermatomycoses are the most common (68.74\%) among all samples of fungal infections. Of the suspected dermatomycosis cases, $12.21 \%$ had positive diagnosis for dermatophytosis.
The identification of fungi is based in micro and macromorphological criteria, both for fungi considered true pathogens and for saprophytic fungi. Direct microscopy examination (DME) has difficulties in differentiating mainly between saprophytic and pathogenic fungi. Culture is needed for isolation and species identification. ${ }^{13}$ Dermatophyte fungi should be considered pathogenic when isolated in culture, while non-dermatophyte fungi can be considered either as contaminants or etiologic agents, and culture should be repeated to reduce the likelihood of a non-dermatophyte fungi being a contaminant. ${ }^{14}$

In our surveys of 3071 suspected cases for dermatomycosis, DME only was requested in 1297 cases, with no culture. Of those, $760(58.6 \%)$ cases were positive with DME; i.e., $41.4 \%$ of the suspected dermatomycosis cases could have presented a false negative re-

TABLE 2: Description of dermatophyte fungi according to the site of isolation from patients seen at the Laboratory of Teaching and Research in Clinical Analysis, Universidade Estadual de Maringá (PR)

\begin{tabular}{|c|c|c|c|c|}
\hline \multirow[t]{2}{*}{ Isolates } & \multicolumn{4}{|c|}{ Area affected } \\
\hline & $\begin{array}{l}\text { Nail } \\
\text { N (\%) }\end{array}$ & $\begin{array}{l}\text { Skin } \\
\text { N (\%) }\end{array}$ & $\begin{array}{c}\text { Hair } \\
\text { N (\%) }\end{array}$ & $\begin{array}{c}\text { Total } \\
\mathbf{N}\left(\%^{* * *}\right)\end{array}$ \\
\hline T. rubrum complex & $187(67.75)$ & $89(32.25)$ & $0(0)$ & $276(73.6)$ \\
\hline T. mentagrophytes complex & $26(60.46)$ & $16(37.21)$ & $01(2.33)$ & 43 (11.47) \\
\hline M. canis & $0(0)$ & $03(9.68)$ & $28(90.32)$ & $31(8.27)$ \\
\hline T. tonsurans & $05(62.5)$ & $0(0)$ & $03(37.5)$ & $08(2.13)$ \\
\hline T. cutaneum & $07(100)$ & $0(0)$ & $0(0)$ & $07(1.87)$ \\
\hline E. floccosum & $0(0)$ & $03(100)$ & $0(0)$ & $03(0.8)$ \\
\hline T. terrestre & $01(50)$ & $01(50)$ & $0(0)$ & $02(0.53)$ \\
\hline M. ferrugineum & $01(50)$ & $01(50)$ & $0(0)$ & $02(0.53)$ \\
\hline Other dermatophytes & $02(66.67)$ & $01(33.33)$ & $0(0)$ & $03(0.8)$ \\
\hline
\end{tabular}

Other dermatophytes: T. gloriae, T. raubitschekii, T. flavescens

$(\% * * *)$ : percentage relative to the total number of isolates (375)

$\mathrm{N}$ : number of samples with positive culture for the specific agent according to the age group

Others: Trichophyton spp

TABLE 3: Description of dermatophyte fungi according to the age group, isolated from patients seen at the Laboratory of Teaching and Research in Clinical Analysis, Universidade Estadual de Maringá (PR)

\begin{tabular}{|c|c|c|c|c|}
\hline & Zero-11 years & $12-19$ years & 20-59 years & $>60$ years \\
\hline & $\mathrm{N}(\%)$ & $\mathrm{N}(\%)$ & $\mathrm{N}(\%)$ & $\mathrm{N}(\%)$ \\
\hline T. rubrum complex & $10(3.62)$ & $13(4.71)$ & $204^{*}(73.91)$ & 49 (17.76) \\
\hline T. mentagrophytes complex & $02(4.65)$ & $02(4.65)$ & $34^{*}(79.07)$ & 05 ( 11.63) \\
\hline M. canis & $29 *(93.56)$ & $01(3.22)$ & $01(3.22)$ & $0(0)$ \\
\hline T. tonsurans & $05(62.5)$ & $0(0)$ & $03(37.5)$ & $0(0)$ \\
\hline T. cutaneum & $0(0)$ & $0(0)$ & $04(57.14)$ & $03(42.86)$ \\
\hline E. floccosum & $0(0)$ & $0(0)$ & $03(100)$ & $0(0)$ \\
\hline T. terrestre & $0(0)$ & $0(0)$ & $02(100)$ & $0(0)$ \\
\hline M. ferrugineum & $0(0)$ & $0(0)$ & $02(100)$ & $0(0)$ \\
\hline Other dermatophytes & 01 (33.33) & $0(0)$ & $02(66.67)$ & $0(0)$ \\
\hline
\end{tabular}

Other dermatophytes: T. gloriae, T. raubitschekii, T. flavescens

$(\% * * *)$ : percentage relative to the total number of isolates (375)

$\mathrm{N}$ : number of samples with positive culture for the specific agent according to the age group $\left({ }^{*} \mathrm{p}<0,05\right)$ 
sult since there was no confirmation through culture. We observed that this situation, commonly occurs in clinical practice, when frequently only the DME is requested. This way, complete laboratory diagnosis is considered a necessary tool to establish the etiology of the disease and aid in choosing the best treatment option. ${ }^{15}$

Cutaneous mycoses are among the most common infections in humans and became an important public health problem, especially because they cause invasive infections in immunosuppressed patients. ${ }^{7,16}$ According to epidemiological data, dermatophytoses whose etiologic agents belong to the genera Trichophyton, Microsporum and Epidermophyton constitute one of the most frequent groups of fungal infections in dermatological practice, followed by non-dermatophyte fungi. ${ }^{2}$

The most frequent agents isolated in the present study were T. rubrum complex(73.6\%), followed by T. mentagrophytes complex $(11.47 \%)$ and $M$. canis $(8.27 \%)$, and these data follows national trends. ${ }^{17-21}$ Comparing these data with studies conducted in Spain and the United States, we can observe the same etiology for T. rubrum complex and T. mentagrophytes complex. ${ }^{18,19}$ It is observed that these dermatophytes are the most common causative agents for nail lesions and are the typical agents in regions with subtropical climate and the southern region of Brazil. ${ }^{21-23}$
Of the samples positive for dermatophytosis, nails represented $66.13 \%$ of the patients affected, in accordance with the literature. ${ }^{6,12,24}$ However, some authors found different ratios: $75 \%, 41 \%$ and $33,85 \%{ }^{20,25,26}$ The skin occupied the second place, being responsible for $24.8 \%$ of the cases, confirming previous studies. And, in third place, we found hair dermatophytosis with $9.07 \%$ of the cases, in accordance with published literature, with $M$. canis being the most frequent causative agent of these infections, primarily affecting children aged zero-11 years, once again in accordance with the literature. ${ }^{3,27}$

Female gender had a higher prevalence in all years, with $57.6 \%$ female cases to $42.4 \%$ male cases. This female vulnerability could be based in the daily life habits of these women, such as using shoes that facilitate onychomycosis. ${ }^{16,20}$

\section{CONCLUSION}

The study made it possible to evidence that dermatomycosis have higher occurrence among all samples of fungal infections from the patients seen, being the nails the most affected area and the fungi T. rubrum complex and T. mentagrophytes complex the most commonly isolated. Therefore, we demonstrate the importance of the analysis of the epidemiological profile of dermatophytes in different regions of Brazil to allow for an appropriate epidemiological conduct for prevention based in the regional frequency of the causative species of dermatophytosis. ${ }^{23}$ 


\section{REFERENCES}

1. Lacaz CS, Porto E, Martins JEC, Heins-Vaccari EM, Melo NT. Tratado de Micologia Médica Lacaz. 9. ed. São Paulo: Sarvier; 2002.

2. Havlickova B, Czaika VA, Friedrich M. Epidemiological trends in skin mycoses worldwide. Mycoses. 2008;51:2-15.

3. Ameen M. Epidemiology of superficial fungal infections. Clin Dermatol. 2010;28:197-201.

4. Charles AJ. Superficial cutaneous fungal infections in tropical countries. Dermatol Ther. 2009;22:550-9

5. Simonnet C, Berger F, Gantier JC. Epidemiology of superficial fungal diseases in French Guiana: a three-year retrospective analysis. Med Mycol. 2011;49:608-11.

6. Zhan P, Liu W. The Changing Face of Dermatophytic Infections Worldwide. Mycopathologia. 2017;182:77-86.

7. Araújo MAR, Libério SA, Guerra RNM, Ribeiro MNS, Nascimento FRF. Mechanisms of action underlying the anti-inflammatory and immunomodulatory effects of propolis: a brief review. Rev Bras Farmacogn. 2012;22:208-19.

8. Lamb FM, Stopiglia CDO, Vetoratto G, Goldani JC, Scroferneker ML. Frequency of onychomycosis in chronic renal failure patients undergoing hemodialysis at a referral hospital in Porto Alegre, Brazil. Acta Dermatovenerol Croat. 2013;21:19-23.

9. Qadim HH, Goldoroushan F, Azimi H, Goldust M. Factors leading to dermatophytosis. Ann Parasitol. 2013;59: 99-102.

10. Murray PR, Rosenthal KS, Pfaller MA. Microbiología médica. 7. ed. Rio de Janeiro: Elsevier; 2014.

11. Wille MP, Arantes TD, Silva JLM. Epidemiologia das dermatomicoses em população da periferia de Araraquara - SP. Rev Bras Clin Med. 2009;7:295-8.

12. Mahalakshmi R, Apoorva R, Joshua J. Dermatophytosis: clinical profile and association between socio-demographic factors and duration of infection. Int J Res Dermatol. 2017:3:282-85.

13. Zanardi D, Nunes DH, Pacheco AS, Tubone MQ, Souza Filho JJ. Evaluation of the diagnostic methods of onychomycosis. An Bras Dermatol. 2008;83:119-24.

14. Souza PR, Vettorato G, Pinto GM, Duquia RP, Amaro TG, Almeira Junior HL, et al. Concordance between direct microscopy and fungical culture for the diagnostic of feet's onychomycosis. An Bras Dermatol. 2012;87:157-9.

15. Azambuja CVA, Pimmel LA, Klafke GB, Xavier MO. Onychomycosis: clinical, mycological and in vitro susceptibility testing of isolates of Trichophyton rubrum. An Bras Dermatol. 2014;89:581-6.
16. Oliveira JAA, Barros JA, Cortez ACA, Oliveira JSRL. Superficial mycoses in the City of Manaus/AM between March and November/2003. An Bras Dermatol. 2006;81:238-43.

17. Cafarchia C, latta R, Latrofa MS, Gräser $\mathrm{Y}$, Otranto D. Molecular epidemiology, phylogeny and evolution of dermatophytes. Infect Genet Evol. 2013;20:336-51.

18. Peres NTA, Maranhão FCA, Rossi A, Martinez-Rossi NM. Dermatophytes: hostpathogen interaction and antifungal resistance. An Bras Dermatol. 2010;85:657667.

19. Dalla Lana DF, Batista BG, Alves SH, Fuentefria AM. Dermatofitoses: agentes etiológicos, formas clínicas, terapêutica e novas perspectivas de tratamento. Clin Biomed Res. 2016;36:230-241.

20. Ribeiro CSC, Zaitz C, Framil VMS, Ottoboni TSC, Tonoli MSC, Ribeiro RP Descriptive study of onychomycosis in a hospital in São Paulo. Braz J Microbiol. 2015;46:485-92.

21. Aquino VR, Constante CC, Bakos L. Frequency of dermatophytosis in mycological examinations at a general hospital in Porto Alegre, Brazil. An Bras Dermatol. 2007;82:239-44.

22. Di Chiacchio N, Madeira CL, Humaire CR, Silva CS, Fernandes LHG, Reis AL. Superficial mycoses at the Hospital do Servidor Público Municipal de São Paulo between 2005 and 2011. An Bras Dermatol. 2014;89:67-71.

23. Schoeler AP, Sguissardi CH, Bernardi E, Cembranel LR, Fuentefria AM. Prevalência de dermatófitos na rotina de micologia em hospital particular de médio porte na cidade de Chapecó, estado de Santa Catarina, Brasil. Rev Ciênc Farm Básica Apl. 2010;31:103-6.

24. Ruiz LRB, Zaitz C. Dermatophytes and dermatophytosis in the city of São Paulo, from August 1996 to July 1998. An Bras Dermatol. 2001;76:391-401.

25. Martelozo IC, Guilhermetti E, Svidzinski TIE. Ocorrência de onicomicose em Maringá, Estado do Paraná, Brasil. Acta Scientiarum. Health Sciences. 2005:27:177-182.

26. Seebacher C, Brasch J, Abeck D, Cornely 0, Effendy I, Ginter-Hanselmayer G, et al. Onychomycosis. Mycoses. 2007;50:321-7.

27. Fernandes NC, Akiti T, Barreiros MGC. Dermatophytosis in children: study of 137 cases. Rev Inst Med Trop Sao Paulo. 2001;43:83-5.

\section{AUTHORS'CONTRIBUTIONS}

Talita Carla Sanguino

(iD) ORCID 0000-0003-0089-9258

Statistical analysis; Approval of the final version of the manuscript; Elaboration and writing of the manuscript; Obtaining, analyzing and interpreting the data; Effective participation in research orientation

Isabele Carrilho Jarros $\quad$ (iD) ORCID 0000-0001-8860-4949

Approval of the final version of the manuscript; Elaboration and writing of the manuscript; Obtaining, analyzing and interpreting the data; Effective participation in research orientation; Critical review of the literature; Critical review of the manuscript

Melyssa Negri

(iD) ORCID

0000-0003-2071-8872

Approval of the final version of the manuscript; Conception and planning of the study; Elaboration and writing of the manuscript; Effective participation in research orientation; Critical review of the literature; Critical review of the manuscript

How to cite this article: Sanguino TC, Jarros IC, Negri M. Occurrence of dermatophytoses in patients from the Sistema Único de Saúde. An Bras Dermatol. 2019;94(3):293-7. 